\title{
Leading-State and the Stability in the International Order
}

\author{
Assit. Prof Inass Abdulsada Ali \\ University of Baghdad - College of Political Science - Dept. of International Studies \\ Baghdad - Iraq
}

\begin{abstract}
:
Leadership, as an organizational behavioral pattern, is a necessity inside the group. Living together requires high-level management to manage relationships and meet needs. In turn, leadership requires a small decision-making unit, because a large group cannot reach a clear and specific vision, and it cannot make quick and decisive decisions. Therefore, the group voluntarily authorizes the leadership authority to a commander who meets the necessary conditions and has the potential to take responsibility for the leadership of the group.

This description applies, largely, to the international community, noting that the question of the authorization of the leadership to a leading State comes spontaneously and dynamically, given the state's position and its abilities and capabilities that respond to the needs of other states.

The international order is characterized by anarchism that rejects the existence of authority over the authority of the state, but at the same time, it needs high-level management to control its interactions and the development of the rules of these interactions, and thus achieve stability in the order, even relatively.

The balance between the two ends of the above equation is achieved through the path of legitimacy. If the legitimacy of the leading state of the order is high among the major powers, the stability will be real and will last for a long period.
\end{abstract}

Keywords: Anarchism; Balance of Power; Disorder; Leadership; Power Arrangement. 